\title{
CAMBIO TECNOLÓGICO Y NUEVA SOCIEDAD DE LA INFORMACIÓN (CIBERSOCIEDAD)(ÚLTIMA PARTE)
}

\section{TECHNOLOGICAL CHANGE AND NEW INFORMATION SOCIETY (CYBERSOCIETY) (LAST PART)}

\begin{abstract}
AUTORES
Luis Joyanes Aguilar: Universidad Pontificia de Salamanca. Licenciado y Doctorado en Ciencias Físicas, Doctor en Informática y Doctor en Sociología. luis.joyanes@aol.com

\section{CURRÍCULUM VITAE}

Universidad Pontificia de Salamanca. Licenciado y Doctorado en Ciencias Físicas, Doctor en Informática y Doctor en Sociología.
\end{abstract}

\section{RESUMEN}

Lo que caracteriza a las nuevas tecnologías es su interdependencia, el hecho de que constituyan un sistema, en el que los avances de cada campo facilitan el progreso en otras áreas de innovación tecnológica en base sobre todo a la comunicabilidad de la información obtenida y a su traducción en el código específico de cada campo por medio de ordenadores telecomunicados entre sí. Es decir, los avances tecnológicos se apoyan en la comunicación de la información obtenida. Esta información facilita la interdependencia de las nuevas tecnologías. Por esta razón es crucial conocer cómo ha evolucionado la información en el tiempo, de modo que un estudio comparado nos ayude a descubrir de qué modo se ha ido produciendo el impacto social de las 
sucesivas tecnologías y cómo se han aprovechado o defendido, en caso negativo, las diferentes culturas.

\title{
PALABRAS CLAVE
}

Cambios - Tecnología - Información - Nueva sociedad

\begin{abstract}
What characterizes the new technologies is their interdependence, that constitute a system in which the progress of each field will facilitate progress in other areas of technological innovation based on all the communicability of the information obtained and its translation specific code in each field through telecommunicated computers together. That is, technological advances are based on the communication of information obtained. This information facilitates the interdependence of new technologies. It is therefore crucial to know how information has evolved over time, so that a comparative study helps us to discover how it has been producing the social impact of successive technologies and how they have used or advocated, if not, different cultures.
\end{abstract}

\section{KEY WORDS}

Changes - Technology - Information - New Company

\section{ÍNDICE}

Séptima parte: LA REVOLUCIÓN SILENCIOSA Y LA CIBERSOCIEDAD

13. La Revolución silenciosa: Los factores del cambio

14. La Nueva Sociedad: La CIBERSOCIEDAD 
Conclusión final

NOTAS

\section{La revolución silenciosa: los factores del cambio}

A medida que nos hemos ido acercando al siglo XXI, Las personas de los países industrializados comenzaron a sentir la sensación de vivir en un mundo que es casi radicalmente diferente de aquel en que nacieron. En poco más de una década -y fundamentalmente los años de la década de los noventa- se han visto cambios culturales, económicos, tecnológicos y políticos en tal escala, que su descripción requiere el uso de la palabra "revolución". Sin embargo, revolución es una palabra asociada -normalmente- a violencia ("La toma de la Bastilla" o el "Bombardeo del Palacio de Invierno", por ejemplo). Realmente esta década ha sido una década violenta, pero la revolución a que nos referimos está provocada por la "información" y poco o nada tiene que ver con la violencia. Revolución de la información es el término más empleado y a él nos referiremos, sin descartar otros sinónimos muy empleados como: "revolución informática".

Si hay algo que es común a todo este proceso revolucionario es el "silencio" con que se está produciendo, y, por ello, nos hemos permitido definirla como "Revolución silenciosa de la sociedad". El símbolo de la revolución es el ordenador. Hoy es una herramienta o dispositivo que se encuentra en casi todos los lugares de nuestra vida: la oficina, la escuela, la mesa de despacho, el hogar, la tienda, etc. Pese a que los últimos cien años se caracterizan por continuas innovaciones tecnológicas, fundamentalmente en tecnologías de la comunicación e inventos tales como el teléfono, la radio la televisión o el radar, el ordenador se percibe como un medio diferente. Es esta diferencia la que define a la nueva sociedad que el ordenador está creando, la revolución que él mismo inspira y conduce. Pero esta nueva sociedad sociedad de la información o cibersociedad- está siendo copilotada en los últimos años por la industria de las telecomunicaciones, y es la simbiosis ordenador- 
telecomunicaciones lo que Al Gore denominó autopistas de la información, que está produciendo el mayor cambio social de la historia -a decir de gran número de sociólogos, economistas y científicos-.

La última revolución comparable con la actual fue la originada por la máquina de vapor. De igual modo que la máquina de vapor fue el motor central de la revolución industrial, el ordenador y las telecomunicaciones (junto a las futuras autopistas de la información) están dirigiendo la revolución que ya se está produciendo y que tendrá su expansión total en el próximo siglo XXI. La nueva sociedad que esta revolución "silenciosa" de la información está propiciando, se encuentra técnicamente apoyada en la multimedia (integración en el ordenador de texto, sonido e imágenes), la realidad virtual (simulación de la realidad mediante ordenador) y autopistas de la información (sistema de comunicaciones interactivas constituido por grandes redes de ordenadores que se conectan entre sí a la velocidad de la luz, merced a medios como la fibra óptica -el cable- los satélites o la telefonía móvil).

La irrupción de la multimedia en la sociedad ha acuñado dos términos: "Infomedia" y "Sociomedia" para definir el impacto que en la propia informática y en la sociedad, en general, se está produciendo. Esta nueva sociedad multimedia, como también se la ha definido, ha creado unas nuevas perspectivas culturales cuya magnitud todavía es difícil de medir, pero que ya son realidad en forma de libro electrónico (disco CDROM, un disco compacto similar a los de audio, que puede contener grabado en una sola unidad una enciclopedia completa como puede ser el Espasa o el Larouse) y periódico electrónico (el periódico publicado en Internet y que se puede leer a diario, a través de la pantalla de un ordenador).

Las TIC han penetrado de lleno en nuestra sociedad. Su utilización se ha hecho extensiva a cualquier sector de actividad. Su abaratamiento está produciendo que los sofisticados sistemas de información se hayan hecho accesibles a una gran mayoría 
de usuarios no especializados. Sáez Vacas llama a este proceso socialización de las Tecnologías de la Información NOTA71. Un análisis de los efectos de esta socialización implicará el análisis de la ética de uso del ordenador en la sociedad, en el contexto del mundo tal y como es, y no como nos gustaría que realmente fuese. Muchos de los numerosos problemas a los que se enfrenta el mundo occidental: políticos, ecológicos, económicos, urbanísticos, raciales, etc. sólo podrán resolverse mediante nuevas aplicaciones de la ciencia y de la tecnología; en este sentido, no hay ninguna tecnología que ofrezca más esperanza en la solución de estos problemas que los ordenadores. A la vez sucede que este tecnología es, seguramente, la que plantea más amenazas a las libertades de las personas.

\section{La nueva sociedad y la globalización: la cibersociedad}

La sociedad de la información o cibersociedad se sustenta en el hecho de que la información es un recurso o un bien económico fundamental y base del desarrollo social actual. La información es un bien que no agota con su consumo, es más, puede que se enriquezca en un desarrollo ideal y utópico hasta valores incalculables, naciendo otra nueva y rica información que cada vez va produciendo más información NOTA72. El centro de atención de las autopistas de la información es la propia información, quedando la llamada autopista y el ordenador en sí como el medio a través del cual se comunica o localiza dicha información.

Esta nueva sociedad que está emergiendo de la revolución de la información combina cambios profundos con una continuidad histórica de la sociedad. En este contexto se ha decidido realizar el estudio del cambio social desde las perspectivas clásicas que hoy más influyen en la sociedad: cambios en el ámbito económico, cambios en el ámbito político y cambios en el ámbito cultural, y desde la "globalización", como conjunto de actuaciones que originadas por el desarrollo científico y tecnológico acercan a unos pueblos a otros, y que por primera vez en la 
historia pone a todos en estrecho e inmediato contacto, abriendo camino hacia una humanidad realmente universal NOTA73.

Los cambios en el ámbito económico obedecen a que la actividad económica gira en torno a la información. Como señala Drucker, si la economía mundial es "capitalista", es el "capitalismo de la información" lo que la domina NOTA74. Los recursos principales productores de riqueza son la información y el saber, y el nuevo saber, como el mismo Drucker ha escrito, ha quedado íntimamente unido a la información.

La información ha transformado las organizaciones, así como su gestión. En la organización tradicional, la mayoría de las personas llamadas directivos no dirigían realmente; lo que hacían era pasar órdenes hacia abajo e informaciones hacia arriba. Si la información está disponible, sobran. Estas ideas de Drucker las plasmó en la ya clásica metáfora de la orquesta sinfónica: "El modelo justo para la organización basada en la información no son las Fuerzas Armadas, aún en su forma modificada; es la orquesta sinfónica en la cual cada músico toca directamente y sin intermediarios para "el presidente ejecutivo", el director, y puede hacerlo porque todos tienen la "misma partitura", es decir la misma información. También lo es el conjunto de jazz, en el cual cada músico asume la responsabilidad de "su partitura" NOTA75.

Drucker va más allá de la organización basada en la información; se ha de llegar a la organización basada en la responsabilidad. En el trabajo del saber, la organización se compone cada vez más de especialistas NOTA76 cada uno de los cuales sabe más de su especialidad que ninguna otra persona en la organización NOTA3 de VA.

Las tecnologías de la información y comunicación (TIC) han tenido un impacto considerable en la cultura. Dejando de lado el impacto de los medios de comunicación clásicos (prensa, radio, televisión) por salirse fuera de nuestra investigación, nos centraremos en la influencia de la multimedia, realidad virtual y 
autopistas de la información en el ámbito cultural y que se denomina "cibercultura": es el nuevo concepto que define la cultura, sociedad y vida de los próximos años, y es un término que engloba todo lo que sea movimiento, evolución y en definitiva cultura a través del prefijo "ciber" que le proporciona un nuevo estado, en el que el canal de desarrollo es su propio flujo tecnológico.

La cibercultura abarca todo el conjunto de posibilidades que ya existían, añadiendo la ventaja de un pensamiento artificial y unos interfaces que simulan los procesos de creación y los transportan a gran velocidad, ya sea en el interior del propio ordenador, o a otros ordenadores situados a distancia. La cibercultura se nutre de la cibernética y del ciberespacio, apoyándose en los factores tecnológicos ya conocidos: Multimedia, Realidad virtual, Autopistas de la información e Internet.

Todos los aspectos de la cultura están siendo influidos por las nuevas tecnologías de la información, y desde el uso del ordenador en las Bellas Artes, pasando por el cine, el deporte, la edición, la música, etc. es difícil encontrar una parcela del ámbito cultural donde no se "sienta" la presencia de la nueva cultura digital. Las nuevas perspectivas culturales en las nuevas sociedades de la información o sociedades digitales se reflejarán en influencias culturales, en la educación y en la religión, además de en otras manifestaciones culturales ya citadas.

La revolución tecnológica está ya invadiendo la educación; dentro de unas décadas habrá transformado la forma en que aprendemos e, incluso, la forma en que enseñamos. El ordenador es mucho más que una herramienta de aprendizaje para los jóvenes, y muy especialmente para los niños hasta los doce o catorce años. Las redes de ordenadores enlazadas vía teléfono, satélite o fibra óptica, harán que la transmisión directa audio, texto y sonido (multimedia) sea tan revolucionaria como el ordenador, y cada vez más será una transmisión bidireccional e interactiva. Las lecciones y conferencias virtuales permitirán que los profesores estén trabajando 
directamente con los alumnos, aunque puedan estar físicamente al otro lado del globo. El sistema de transmisión por satélite hace posible el acceso a una enseñanza de alta calidad para el país más pobre y la aldea más remota.

Cuanta más educación (instrucción) tenga una persona, más a menudo necesitará más instrucción NOTA77. El sistema educativo será cada vez más abierto, y permitirá que una persona se incorpore a cualquiera de sus etapas a cualquier edad. Las escuelas, colegios y universidades tendrán que competir con otros proveedores de enseñanza y aprendizaje, como centros de formación presenciales y virtuales de grandes empresas, universidades a distancia "virtuales".

Otro ámbito donde la sociedad de la información está ejerciendo un gran impacto es el ámbito político. La informatización y las telecomunicaciones influyen en la vida política de la sociedad de dos formas distintas: primero, la tecnología de la información exige respuestas políticas públicas; el segundo tipo de influencia se deduce de la naturaleza fundamental de la tecnología de la información, que permite influir en la toma de decisiones, así como en la planificación y control de al gestión de recursos públicos y privados.

Los nuevos sistemas de información, con sus posibilidades de almacenamiento y tratamiento de la documentación y la recuperación de la información, se convierten o se pueden convertir en instrumento de presión y control social. Por otro lado, las cantidades masivas de información que hoy día se manejan exigen de autoridades públicas, organismos y empresas, así como de particulares, un uso correcto de la misma. Se requiere así la protección de la información como garantía de su integridad y como defensa de los derechos que sobre ella ejerce, o puede ejercer su titular. La protección de los datos personales no sólo ha de estar reconocida, como lo está, en las modernas legislaciones, mediante el derecho a la intimidad, sino que también ha de proteger todo lo que entraña el término anglosajón privacidad. 
Es por ello necesario regular la información como recurso económico por excelencia de la nueva sociedad de la información. Los creadores de información crean una propiedad valiosa, que estará sometida a las leyes del mercado, y así aparecerán creadores, propietarios y usuarios, consumidores individuales o beneficiarios de información. El aparato del Estado habrá de regular todas las interacciones entre los agentes exteriores, y será también a su vez creador, proveedor y usuario de información; es decir, la conocida regla social de "juez y parte".

¿Cuál es el rol del Estado desde el punto de vista político en la cibersociedad? En esencia, el Estado puede intervenir de cuatro formas, entre el propietario y el buscador o usuario de información. Primero debe proteger la información como una propiedad en la que los derechos pertenecen claramente a su propietario legal; esta es la función de las leyes de propiedad intelectual o de Copyright. Segundo el Estado debe evitar el uso no autorizado de información que haya sido adquirida, creada o reunida legalmente; este es el propósito de las leyes de protección de datos y privacidad personal. Tercero, el Estado debe garantizar el derecho de acceso a ciertas categorías de información de interés o beneficio para sus ciudadanos; esto se consigue con legislación sobre libertad de información. Cuarto, el Estado debe evitar la diseminación de información vital; esto ha de hacerse por razones de seguridad, moralidad o conveniencia política, y evidentemente es una de las áreas más difíciles de explorar, y evoca el temido término de censura.

\section{CONCLUSIÓN FINAL}

Las innovaciones tecnológicas junto con el cambio tecnológico que han producido han hecho que el proceso de globalización sea continuo: no se detiene, es irreversible como - por desgracia- ha sido la desaparición de centenares de culturas autóctonas en los últimos cien años. 
La información ha sido un bien escaso que monopolizaban personas y organizaciones, desde la aparición del lenguaje para la comunicación oral. La revolución de la información ha modificado radicalmente la organización de las grandes empresas que se diseñaron con ideas y organización centralizadora y ahora han pasado a descentralizarse casi en su totalidad, con grandes beneficios para estructuras aisladas eficientes y han abierto la posibilidad del trabajo a domicilio y el teletrabajo NOTA78.

Estamos de acuerdo con Negroponte en que la era digital (sociedad de la posinformación) que viviremos en el próximo milenio será más descentralizadora, globalizadora, armonizadora y permisiva NOTA79. El cambio tecnológico auspiciado por las TIC hará realidad -al menos en teoría- la utopía de la aldea global -una nueva humanidad sin fronteras- no sin afrontar graves riesgos, lo que conllevará estar preparado técnica y culturalmente ante los nuevos retos de la cibersociedad o nueva sociedad de la información del siglo XXI.

NOTAS

NOTA 71: SÁEZ VACAS, Tecnologías de la Información, Ordenadores Personales y P.I.P.C., BIT, 11, 56, págs. 37-46.

NOTA 72: M. A. DAVARA RODRÍGUEZ, De las autopistas de la información a la Sociedad virtual, Aranzadi, 1996, pág. 50. 
NOTA 73: I. HERNANDO DE LARRAMENDI, Crisis de la Sociedad. Reflexiones para el siglo XXI, Madrid, Actas, 1995, pág. 210. Esta obra, escrita por un eminente empresario, experto en el mundo del Seguro -creador de MAPHRE-, con una larga vida empresarial y pública, ha recogido en la $\mathrm{V}$ y última parte de la misma un notable estudio sobre la globalización en su sentido más genérico.

NOTA 74: PETER DRUCKER, La sociedad poscapitalista, Barcelona, Apóstrofe, $2^{\mathrm{a}}$ reimpresión, 1995, pág. 181.

NOTA 75: Ibíd., pág. 111.

NOTA 76: Aunque Drucker no lo cita expresamente, esos especialistas, hoy día, utilizan de una u otra forma información, y prácticamente, con herramientas informáticas y telemáticas acceden, buscan, procesan y difunden información. EN el prefacio de una de sus últimas obras (La gestión en un tiempo de grandes cambios, Barcelona, Edhasa, 1995) [publicación del original en inglés] hace ver que hace diez años nadie podía predecir que la mayor repercusión que la revolución de la información tendría en la economía sería una forma radicalmente nueva de plantear y estructurar el más viejo sistema de información: el modelo de contabilidad de los "cuenta habichuelas".

NOTA 77: DRUCKER, op. cit., pág. 203.

NOTA 78: LUIS JOYANES, Cibersociedad: Realidad o utopía, Universidad Pontificia de Salamanca en Madrid, 1996, pág. 469.

NOTA 79: NICHOLAS NEGROPONTE, El mundo digital, Barcelona, Ediciones B, 1995. 
NOTA 3 DE VIVAT ACADEMIA: Queremos hacer notar que los responsables actuales de la política universitaria, (Véase el "Informe Bricall") se aferran como pueden a la vieja idea de mantener jerarquizada la estructura universitaria, en contra de las tendencias actuales. Es más, están propiciando la aparición de nuevos estudios en los que los licenciados no son especialistas en nada, sino que poseen una mínima información sobre un conjunto demasiado amplio de ramas del conocimiento, (un claro ejemplo es la Licenciatura en Medio Ambiente).

La nueva sociedad de la información, donde ésta fluye directamente, sin obstáculos, y a velocidad de la luz, está exigiendo la integración de numerosos especialistas, buenos conocedores de las auténticas ciencias y tecnologías, en grupos de trabajo cada vez más interdisciplinares.

La Universidad española no ha sabido encajar el golpe de la revolución de la información y, quizás por primera vez en la historia, está muy lejos de ser motor de los nuevos cambios. Es verdaderamente incomprensible observar como en el seno de la universidad se pueden encontrar las reticencias mayores a adoptar las nuevas formas que exige la CIBERSOCIEDAD; no sólo entre sus directivos, sino, lo que es peor, entre el propio profesorado, que se supone ha de estar a la última en las necesidades sociales. 